\title{
SMOOTH TRANSITIONS: ASSESSMENT AND ADVANCEMENT OF LEVEL 2 WRITING STUDENTS AT HOUSTON COMMUNITY COLLEGE
}

\author{
Devin McCain, \& Claudia Pena \\ Houston Community College, Houston, TX (USA)
}

\begin{abstract}
Houston Community College's Intensive English program was started by Maria Bazan-Myrick in 2012 and operates at nine campuses around Houston that sometimes educate upwards of 12,000 ESL learners per academic year. It consists of five levels, the first three of which (Intro, Level 1, and Level 2) are taught by Continuing Education-Languages instructors. The program received the Exemplary Program Award from the National Council for Continuing Education \& Training in 2013, and was awarded for being the top performer at HCC in 2017. Ongoing assessment of both students and the practices of the program has been vital to its success, and the idea for this workshop originated from a student learning objective (SLO) data analysis of students who took Level 2 courses during the Summer 2018 semester.

The purpose of this workshop is to foster discussion about building a strong writing foundation in an ESL curriculum. By the end of this workshop, participants will be able address questions about how to build the curriculum, how to meaningfully assess student performance, and how to promote development of students' writing skills.
\end{abstract}

Keywords: Writing, evaluation, data analysis, ESL.

\section{Opening exercise (slides 2-3)}

This workshop will be conducted via PowerPoint. The presenters will first guide the participants through a calibration activity.

\subsection{Calibration activity (slide 2 )}

Participants will be presented with writing samples produced by various students who have taken Continuing Education-Languages courses at Houston Community College and copies of the rubric that instructors in the program use to grade students' writing samples. Using the rubric and their own ideas about quality writing, they will be given a few minutes to evaluate each sample and assign it a level.

\subsection{Calibration activity review (Slide 3)}

The presenters w i 11 reveal the levels that they assigned to each sample. The participants will be given the opportunity to identify the key differences between each sample and discuss whether or not they agree with the presenters' assignments.

\section{SLO analysis (slides 4-6)}

The presenters will share and review results of a student learning objective (SLO) data analysis that focuses on the writing test results of a cohort of 97 Level 2 students who took summer Continuing Education-Languages courses.

\subsection{Background (slides 4-5)} participants.

The presenters will explain the methodology, scope, and limitations of the SLO analysis to the

\subsection{Results (slide 6)}

The presenters will share and review the results of the SLO analysis with the participants. The most noteworthy results are listed in Figures 1 and 2 below. 
Figure 1. Grades Received by Site.

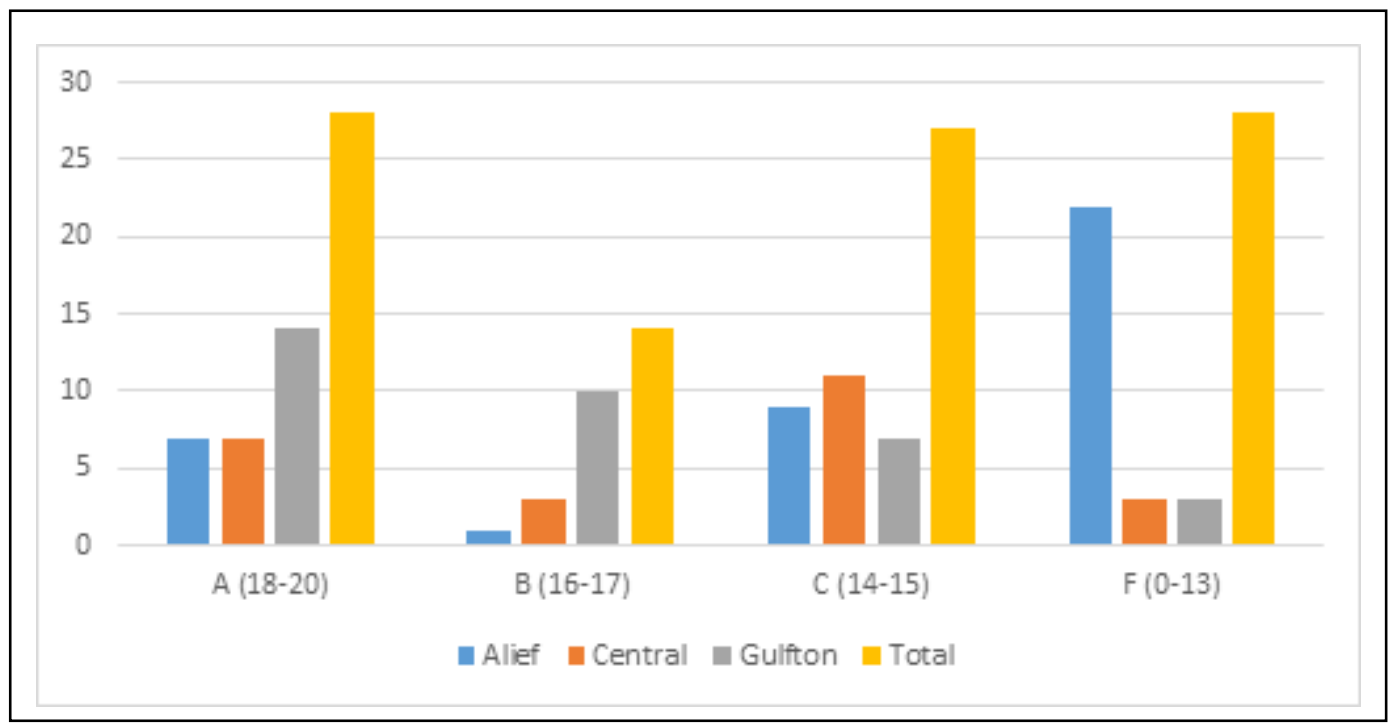

Figure 2. Passing and Non-Passing Grades by Site.

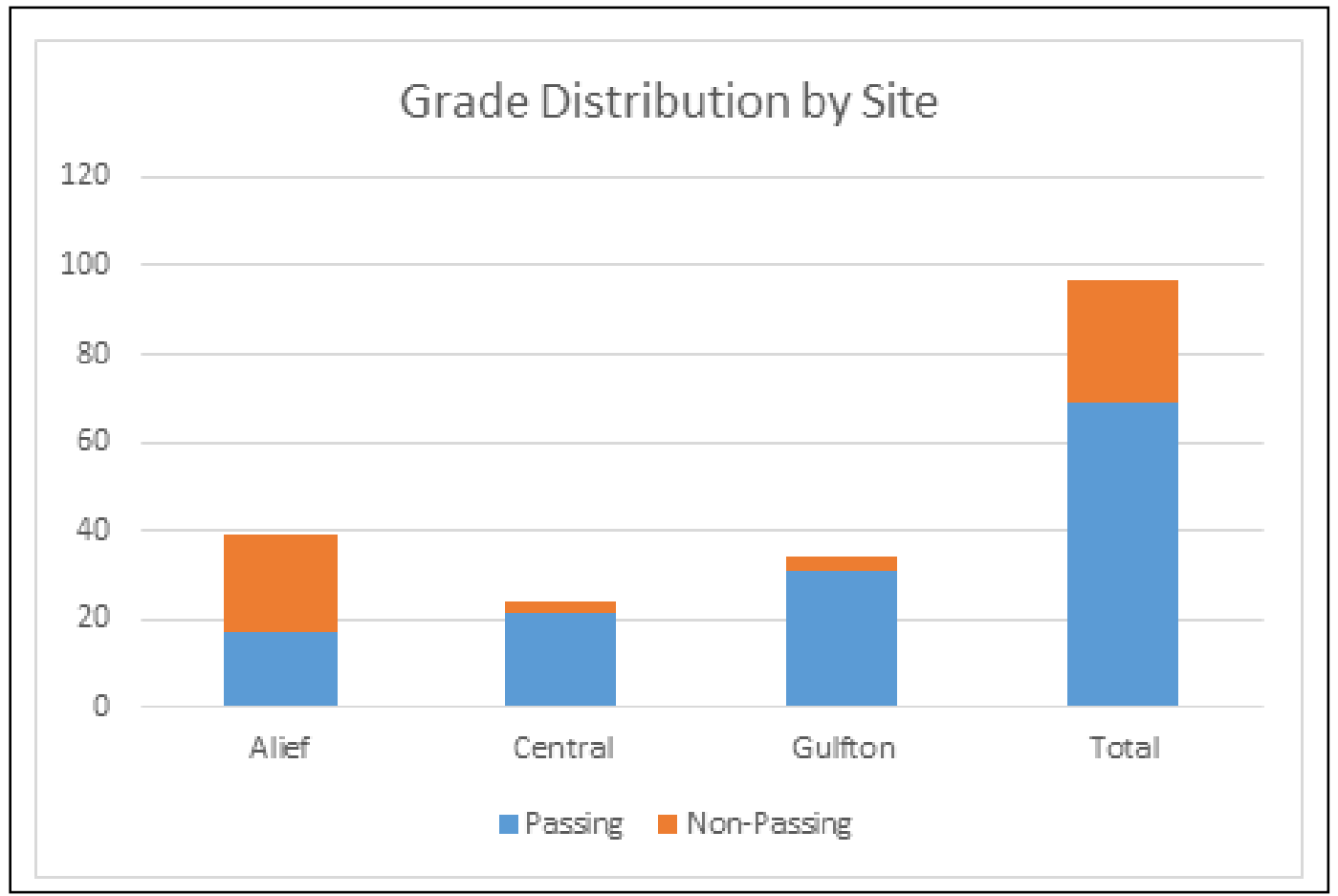

\section{Conclusions (slide 7)}

The presenters will provide a list of suggestions for improving student performance in areas where numerous errors were observed, as detailed in Figure 3 on the next page. 
Figure 3. Suggestions for Improving Students' Scores.

\begin{tabular}{|l|ll|}
\hline Spelling & - & Focus on teaching phonics in Listening \& Speaking classes \\
& - & Teach common spelling rules \\
- & $\begin{array}{l}\text { Teach word forms and suffixes that change the form of words (e.g. - } \\
\text { tion, -ment, -ize) }\end{array}$ \\
\hline Transitions & - & $\begin{array}{l}\text { Focus on teaching conjunctions and the purpose of different transition } \\
\text { words/phrases } \\
\text { Emphasize importance of transitioning between different ideas in } \\
\text { paragraphs and essays }\end{array}$ \\
\hline Verb forms & - & $\begin{array}{l}\text { Focus on the proper situations in which to use various verb tenses } \\
\text { - }\end{array}$ \\
\hline Prepositions & - Focus on moods (e.g. subjunctive) \\
\hline Capitalization & Emphasize the proper use of gerunds and infinitives \\
\hline Punctuation & - & $\begin{array}{l}\text { Stress meanings and usage of common prepositions } \\
\text { and titles }\end{array}$ \\
\hline Outlines & - $\begin{array}{l}\text { Stress proper placement of commas after dependent clauses and full } \\
\text { stops (or semicolons) after independent clauses }\end{array}$ \\
\hline
\end{tabular}

\section{Discussion \& evaluation (slide 8)}

The presenters will share a list of outstanding questions raised by the SLO analysis and the current evaluation standards that they will discuss with the participants.

The presenters are aware that the structure of the program in which they teach is very different from those of other higher education institutions. In sharing this information, they hope to elevate awareness of the diversity of ESL program structures and collect and share information that will help HCC and other institutions improve student writing and assessment processes.

\section{References}

No references were used. This was practical analysis of student data as given by teachers. 